\title{
АМЕРИКАНСКИЙ ПОДХОД УРЕГУЛИРОВАНИЯ ПРАВОВОГО ПОЛЯ ЦИФРОВОГО ДОКУМЕНТООБОРОТА: КОЛЛИЗИИ И РЕШЕНИЯ
}

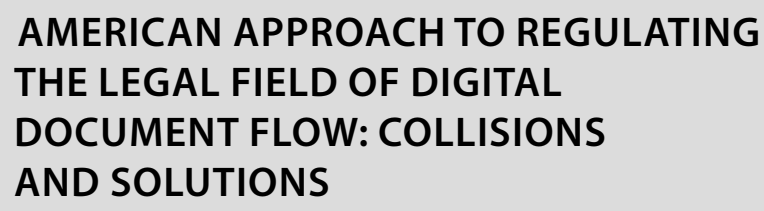

AMERICAN APPROACH TO REGULATING THE LEGAL FIELD OF DIGITAL DOCUMENT FLOW: COLLISIONS AND SOLUTIONS

\section{Nikitenkova}

Summary. Digitalization sets the vector along which socio-economic systems will develop at the micro and macro levels in the long term. Comprehensive analysis of processes related to the digital form of workflow and ensuring information security of data is especially important in the context of new hybrid threats that dictate new rules of behavior. The author systematizes this broad topic of digital services regulation and electronic document management, taking into account the experience of the United States, a leader in digital transformation. The American model of creating a solid legal framework for the implementation of the digitalization process in the use of document circulation and personal data protection is revealed. In addition, directions for improving these processes for Russia are formulated.

Keywords: digital transformation, digital government, national digital sovereignty, state regulation, information and communication technologies, ICT standardization, artificial intelligence, platform compatibility, USA.

\author{
Никитенкова Мария Александровна \\ К.э.Н., С.н.С., ФГБУН Институт США и Канады \\ Российской академии наук \\ maria.nikitenkova@mail.ru
}

Аннотация. Цифровизация задает вектор, по которому будут развиваться социально-экономические системы на микро- и макроуровнях на долгосрочную перспективу. Особо важен в условиях новых гибридных угроз, диктующих новые правила поведения, всесторонний анализа процессов, связанных сцифровой формой документооборота и обеспечения информационной безопасности данных. В статье систематизируется данная обширная тема регулирования цифровых сервисов и управления электронной документацией с учетом опыта лидера цифровой трансформации США. Раскрывается американская модель создания прочного правового поля для осуществления процесса цифровизации в применении документооборота и защиты персональных данных. Сформулированы направления совершенствования данных процессов для России.

Ключевые слова: цифровая трансформация, цифровое правительство, национальный цифровой суверенитет, государственное регулирование, информационно-коммуникационные технологии, стандартизация ИКТ, искусственный интеллект, совместимость платформ, США.

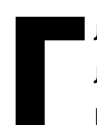

лобализация глобальных экономических и технологических процессов, мощная конкуренция, геополитические реалии и гибридные угрозы приводят к новым правилам поведения для стран и регионов мира. Перспективы развития и социально-экономическая стабильность отдельных стран зависят от заботы об основах их национальной безопасности, а также от укрепления политической и экономической независимости. Все современные инструменты или информационно-коммуникационные технологии вносят значительный вклад в преобразование общества, потому что информация является важнейшим источником развития во всех сферах функционирования государства [7].

Лидером указанных процессов являются Соединенные Штаты, которые, как и весь мир, переживают замечательную экономическую и социальную трансформацию, движимую технологиями. В этом меняющемся мире экономический рост и конкурентоспособность все больше связаны с цифровой экономикой, которая является ключевым фактором создания рабочих мест, создания бизнеса и инноваций. А в современной цифровой экономике люди во всем мире обмениваются идеями, осваивают новые навыки и получают доступ к хранилищу человеческих знаний [6].

Эта технологическая революция была драматичной для США. В 1995 году только 45 миллионов человек имели доступ к Интернету. В 2020 году около 4,8 миллиардов человек имели доступ к Интернету. Цифровая экономика оказывает колоссальное влияние на рабочие места и экономический рост в США. Например, они экспортируют около 400 миллиардов долларов в виде услуг, оказываемых в цифровом формате, что составляет более половины экспорта услуг США и около одной шестой всего экспорта товаров и услуг США [9].

Вот почему Министерство торговли делает политику в области технологий и Интернета своим главным приоритетом, инвестируя ресурсы для решения проблем и возможностей, с которыми бизнес сталкивается в цифровой экономике. Поэтому в 2016 г. в США запу- 
стили на реализацию «Digital Economy Agenda» («Повестку по цифровой экономике»), посвященную четырем ключевым возможностям [5, 7]:

1. Глобальный свободный обмен информацией. Свободный и открытый глобальный Интернет с минимальными препятствиями для потоков данных и услуг через границы является краеугольным камнем успеха цифровой экономики. Содействие свободному и открытому Интернету, потому что Интернет лучше всего работает для предприятий и сотрудников, когда данные и услуги могут беспрепятственно перемещаться через границы.

2. Повышение доверия в сети, поскольку безопасность и конфиденциальность имеют важное значение для процветания электронной торговли.

3. Цифровые навыки и доступ к ним. Американские предприятия и потребители нуждаются в быстрой инфраструктуре и квалифицированной рабочей силе для процветания в оцифрованной глобальной экономике. Обеспечение доступа для работников, семей и компаний, так как быстрые широкополосные сети имеют важное значение для экономического успеха в XXI веке. Американскому бизнесу нужна внутренняя структура, которая будет способствовать глобальному доверию, а также международные правила, которые не обременяют американские фирмы несправедливым бременем.

4. Содействие инновациям с помощью разумных правил интеллектуальной собственности и продвижения нового поколения захватывающих новых технологий. Торговля может играть роль в поддержке инноваций, в том числе хороших правил интеллектуальной собственности. Существуют возможности для поддержки новых технологий и выявления долгосрочных политических проблем на ранних этапах жизненного цикла разработки.

Таким образом, Интернет и цифровая экономика становятся важнейшей частью будущего успеха американской экономики в целом. Они являются источником рабочих мест; способствующий развитию мировой торговли; и ключевой элемент конкурентоспособности США [7, 8]:

- На цифровую экономику уже приходится более пяти процентов валового внутреннего продукта США, но эта цифра не отражает ее истинный потенциал.

- По оценкам экспертов, цифровизация может увеличить годовой ВВП США до 2,2 триллиона долларов к 2025 году.

- Соединенные Штаты являются крупнейшим мировым экспортером услуг.
Государственное управление США проводит мероприятия в рамках указанной выше Повестки, чтобы обеспечить процветание американских предприятий и потребителей в период быстрых технологических изменений и глобальной конкуренции. Эта инициатива основывается на работе 12 бюро Департамента и почти 47000 сотрудников, расположенных во всех 50 штатах и более чем 86 странах мира, и дополняет Повестку Департамента в области инноваций и инициативы в области данных. Повестка цифровой экономики предназначена для создания скоординированной стратегической программы работы всего Департамента по поддержке американской промышленности и потребителей, а также преобразующей силы Интернета и других цифровых технологий.

Можно согласиться, что практически каждая современная компания полагается на Интернет для своего роста и процветания, он помогает предприятиям и потребителям осознать потенциал цифровой экономики для ускорения роста и расширения возможностей как в США, так и во всем мире $[4,10]$. Одним из важнейших направлений являются меры для развития Интернета вещей (ІоТ). В «зеленой книге» исследуются преимущества и проблемы меняющегося ландшафта Интернета вещей и предлагается, чтобы правительство США продолжало создавать благоприятную среду для роста и процветания инновационных технологий. Интернет вещей обещает произвести революцию в современном мире: от повышения эффективности и удобства для промышленности, потребителей и правительства до повышения безопасности. Поэтому в США множество усилий направлены на создание условий для развития новых технологий и определяют будущие действия, необходимые для поддержки развития и расширения Интернета вещей. Можно выделить четыре широкие области взаимодействия, связанные с ІоT $[7,8]$ :

1. Обеспечение доступности и доступа к инфраструктуре: укрепление физических активов и ресурсов, связанных с использованием спектра, необходимых для поддержки роста и развития Интернета вещей.

2. Создание сбалансированной политики и создание коалиций: устранение препятствий и поощрение координации и сотрудничества; влияние, анализ, разработка и продвижение норм и практик, которые будут защищать пользователей Интернета вещей, одновременно способствуя росту, развитию и применимости технологий Интернета вещей.

3. Содействие стандартам и развитию технологий: обеспечение разработки и внедрения необходимых технических стандартов для поддержки глобального взаимодействия ІоТ, а также дальнейшего развития технических приложений и устройств для поддержки Іо Т. 
4. Поощрение рынков: содействие развитию Интернета вещей за счет использования приложений и цифровых технологий; передача экономических выгод и возможностей Интернета вещей иностранным партнерам.

Еще одним важным аспектом цифровой трансформации является электронное правительство. Это связано с тем, что государственное управление - очень важный элемент функционирования страны, а каждый гражданин пользуется услугами государственного сектора. В настоящее время в результате развития информационного общества одной из его основных задач является создание и развитие цифровых сервисов в государственном управлении. Использование новых технологий, таких как Интернет, при предоставлении электронных услуг в сфере государственного управления, в первую очередь, предназначено для улучшения функционирования польских офисов, а также для повышения удовлетворенности и желания пользоваться административными услугами со стороны граждан и предпринимателей. Функционирование электронного правительства также экономит время и позволяет решать официальные вопросы независимо от места пребывания и времени суток. Развитие электронного администрирования выгодно для граждан, предпринимателей и самих офисов. Существование электронного правительства во многом основано на обработке различных типов документов и управлении ими. [2]

Основным требованием для успешной реализации стратегии электронного правительства является правильная структура. Они относятся к трем входным факторам: - законодательные нормы, • инфраструктура широкополосной связи и - уровень образования. Что касается юридических требований, правительства обычно открывают новые возможности, что затрудняет их быстрое выполнение на нескольких политических уровнях. В прошлом вопросы о вариантах аутентификации, цифровой согласованности или стандартах безопасности данных не входили в число специализированных областей политики и администрирования. Данная работа началась в США, а потом стала одним из приоритетов государственной политики других стран мира. С ростом оцифровки и переходом к обществу знаний эти темы и их правовая структура становятся элементарными. В федеральных структурах, таких как Германия и США, также необходимо учитывать и интегрировать различные политические уровни. Не менее сложен и вопрос о подходящей и эффективной инфраструктуре. Развитое предложение широкополосного Интернета постоянно находится в центре внимания политиков, так как оно связано с производительностью в цифровом мире [4].
Третье поле исследований в этой области - уровень образования населения. Помимо правовых и инфраструктурных требований, также необходимо уточнить, насколько граждане подготовлены системой образования к вызовам постоянно растущей интенсивности знаний в бизнесе и обществе. Чем более сложными становятся приложения в цифровом мире, тем более необходимы онлайн-навыки, то есть технические знания и способность использовать эти возможности.

В США, ЕС и России в настоящее время существует множество инициатив по генерированию инновационных импульсов на основе общедоступных данных. На фоне постоянно появляющихся новых бизнес-моделей, основанных на больших данных и в целом более сильной ориентации экономики на знания, эти подходы являются очень многообещающими. Простые, но в то же время безопасные процессы аутентификации, цифровая согласованность услуг, отчеты о состоянии и оптимизация приложений для мобильных устройств также относятся к этой области. Несмотря на это, в течение некоторого времени в России растет осознание того, что страна находится в проигрышном положении, когда дело доходит до технологической независимости и самодостаточности - ее обгоняют как США, так и Китай. Россия по-прежнему зависит от американских технологий и компонентов, а также производственная ситуация, вызванная коронавирусом, и фактический разрыв цепочек поставок во время самых жестких ограничений. Поэтому важным становится цифровой суверенитет, который означает увеличение технологических возможностей и способность влиять на то, какие правила и ценности управляют миром, сосредоточенным вокруг новых технологий, в котором другие страны начинают доминировать. Текущие исследования показывают, что в этом секторе России все еще существует большой потенциал для улучшения [1, 3].

Несмотря на предпринимаемые меры по цифровой трансформации в США существует серьезная проблема: в стране нет единого закона, регулирующего конфиденциальность всех типов данных. Вместо этого у него есть смесь законов, которые называются такими аббревиатурами, как HIPAA, FCRA, FERPA, GLBA, ECPA, COPPA и VPPA. В настоящее время законы о конфиденциальности представляют собой беспорядок из различных отраслевых правил. Исторически сложилось так, что в США существует множество несопоставимых федеральных и региональных (на уровне штатов) законов, которые либо направлены на определенные типы данных, такие как кредитные данные или информация о здоровье, либо - определенные группы населения, такие как дети, пенсионеры, и регулируют в этих сфеpax [8]. 
Данные, собираемые подавляющим большинством продуктов, которые люди используют каждый день, не регулируются. Поскольку нет федеральных законов о конфиденциальности многие компании в значительной степени свободны делать с данными все, что захотят, если в штате нет своего собственного закона о конфиденциальности данных (подробнее об этом ниже). В большинстве штатов компании могут использовать, передавать или продавать любые данные, которые они собирают о гражданах, без уведомления их об этом. Ни один национальный закон не устанавливает стандартов, когда (или если) компания должна уведомлять гражданина, если его данные были взломаны или доступны неавторизованным сторонам. Если компания передает данные, включая конфиденциальную информацию, такую как здоровье или местонахождение, третьим лицам (например, брокерам данных), эти третьи стороны могут в дальнейшем продавать или делиться ими, не уведомляя никого.

Таким образом, цифровая трансформация является глобальным трендом, при этом отдельные государства, прежде всего, США, оказываются всегда впереди. Россия также проводит работу в данном направлении, однако существуют области для совершенствования и модернизации: подготовка единой системы электронного документооборота между государственными органами различных уровней управления и разработка единого стандарта для всех систем в государственном управлении. Возникающая среда может быть основана на облачной технологии, которая обеспечит легкий доступ к приложению для отдельных государственных административных единиц без необходимости расширения собственной ИТ-базы. Благодаря внедрению инструментов электронного управления документацией государственное управление может достичь ощутимых преимуществ, обеспечивая способность различных организаций и систем ИКТ, используемых этими организациями, а также публичных реестров, сотрудничать для достижения взаимовыгодных и ранее согласованных целей, принимая во внимание обмен всей информацией и знаниями посредством конкретных поддерживаемые ими бизнес-процессы, которые осуществляются посредством обмена данными с использованием систем ИКТ этими субъектами.

\section{ЛИТЕРАТУРА}

1. Зиновьева Е.С., Булва В.И. Цифровой суверенитет Европейского союза. Современная Европа, 2021, № 2, сс.40-49

2. Зорина А.Э. Совершенствование государственной политики в сфере развития цифровой экономики. Экономика нового мира. 2018 . № 2 (10). сс.16-25.

3. Мамедов В.Р. Влияние технологического прогресса на трансформацию сущности государственного суверенитета. Инновации и инвестиции, 2021, № 8, сc.21-25.

4. Blankertz A., Jaursch J. How the EU plans to rewrite the rules for the internet. 2020. Available at: https://www.brookings.edu/techstream/how-the-eu-plansto-rewrite-the-rules-for-the-internet/ (accessed 05.12.2021).

5. Corrado, C., Haskel, K. and Jona-Lasinio, C. Knowledge Spillovers, ICT and Productivity Growth. Oxford Bulletin of Economics and Statistics, 2017, 79, pp. 592698.

6. Floridi, L. The Fight for Digital Sovereignty: What It Is, and Why It Matters, Especially for the EU. Philos. Technol. 2020, 33, 369-378. https://doi.org/10.1007/ s13347-020-00423-6

7. Morley, J., Cowls, J., Taddeo, M., \& Floridi, L. (2020). Ethical guidelines for COVID-19 tracing apps. Nature, 2020,582, 29-31.

8. Runde D.F., Bandura R., Ramanujam S. The United States Has an Opportunity to Lead in Digital Development. Available at: https://csis-website-prod. s3.amazonaws.com/s3fs-public/publication/210330_Runde_Digital_Development.pdf?jYnPoJ24ircT3iTGdHHy503qhsyRso3r (accessed 05.12.2021).

9. Statistics World Bank. Available at: https://datacommons.org/place/country/USA?hl=ru (accessed 05.12.2021).

10. Alshibly H, Chiong R, Bao Y Investigating the Critical Success Factors for Implementing Electronic Document Management Systems in Governments: Evidence From Jordan. Information Systems Management, 2016, no 33(4), pp.287-301. 